\title{
Sunitinib-associated hypertension and neutropenia as efficacy biomarkers in metastatic renal cell carcinoma patients
}

Frede Donskov ${ }^{*}, 1$ M Dror Michaelson ${ }^{2}$, Igor Puzanov ${ }^{3}$, Mellar P Davis $^{4}$, Georg A Bjarnason ${ }^{5}$, Robert J Motzer ${ }^{6}$, David Goldstein ${ }^{7}$, Xun Lin ${ }^{8}$, Darrel P Cohen ${ }^{8}$, Robin Wiltshire ${ }^{9}$ and Brian I Rini ${ }^{10}$

${ }^{1}$ Department of Oncology, Aarhus University Hospital, Norrebrogade 44, Aarhus C 8000, Denmark; ${ }^{2}$ Massachusetts General Hospital Cancer Center, The Claire and John Bertucci Center for Genitourinary Cancers, 55 Fruit Street, Yawkey 7E, Boston, MA 02114, USA; ${ }^{3}$ Division of Hematology-Oncology, Vanderbilt University Medical Center, 2220 Pierce Avenue, 777 Preston Research Building, Nashville, TN 37232-6307, USA; ${ }^{4}$ Palliative Medicine and Supportive Oncology Services, Division of Solid Tumor, Cleveland Clinic Taussig Cancer Institute, 9500 Euclid Avenue, Desk R35, Cleveland, OH 44195, USA; ${ }^{5}$ Division of Medical Oncology, Sunnybrook Odette Cancer Centre, 2075 Bayview Avenue, Toronto, ON M4N 3M5, Canada; ${ }^{6}$ Department of Medicine, Genitourinary Oncology Service, Memorial Sloan-Kettering Cancer Center, 1275 York Avenue, New York, NY 10021, USA; ${ }^{7}$ Department of Medical Oncology, Prince of Wales Hospital, Randwick, NSW 2031, Australia; ${ }^{8}$ Pfizer Oncology, 10646 Science Center Drive, La Jolla, CA 92121, USA; ${ }^{9}$ Pfizer Oncology, Walton Oaks, Dorking Road, Walton-on-the-Hill, Tadworth, Surrey KT20 7NS, UK and ${ }^{10}$ Cleveland Clinic Taussig Cancer Institute, Glickman Urological Institute, 9500 Euclid Avenue, Desk R35, Cleveland, $\mathrm{OH}$ 44195, USA

Background: Metastatic renal cell carcinoma (mRCC) prognostic models may be improved by incorporating treatment-induced toxicities.

Methods: In sunitinib-treated mRCC patients $(N=770)$, baseline prognostic factors and treatment-induced toxicities (hypertension (systolic blood pressure $\geqslant 140 \mathrm{~mm} \mathrm{Hg}$ ), neutropenia (grade $\geqslant 2$ ), thrombocytopenia (grade $\geqslant 2$ ), hand-foot syndrome (grade $>0$ ), and asthenia/fatigue (grade $>0)$ ) were analysed in multivariate analyses of progression-free survival (PFS) and overall survival (OS) end points.

Results: On-treatment neutropenia and hypertension were associated with longer PFS ( $P=0.0276$ and $P<0.0001$, respectively) and $O S(P=0.0014$ and $P<0.0001$, respectively), independent of baseline prognostic factors, including International Metastatic Renal Cell Carcinoma Database Consortium (IMDC) criteria. By 12-week landmark analysis, neutropenia was significantly associated with longer PFS and OS $(P=0.013$ and $P=0.0122$, respectively) and hypertension or hand-foot syndrome with longer OS $(P=0.0036$ and $P=0.0218$, respectively). The concordance index was 0.65 ( $95 \% \mathrm{Cl}: 0.63-0.67)$ for IMDC classification alone and $0.72(95 \% \mathrm{Cl}: 0.70-0.74)$ when combined with hypertension and neutropenia. Considering hypertension and neutropenia (developing both vs neither) changed IMDC-predicted median OS in each IMDC risk group (favourable: 45.3 vs 19.5 months; intermediate: 32.5 vs 8.0 months; poor: 21.1 vs 4.8 months).

Conclusions: On-treatment neutropenia and hypertension are independent biomarkers of sunitinib efficacy and may add prognostic accuracy to the IMDC model.

*Correspondence: Dr F Donskov; E-mail: fd@oncology.au.dk

Received 5 January 2015; revised 18 August 2015; accepted 23 September 2015; published online 22 October 2015

(c) 2015 Cancer Research UK. All rights reserved 0007-0920/15

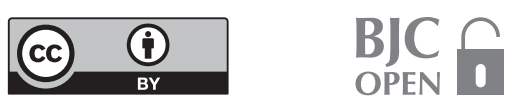


The rapid development and approval of several molecularly targeted agents for the treatment of advanced renal cell carcinoma (RCC) has resulted in significant clinical benefit to patients by providing multiple treatment options. The identification of baseline prognostic criteria has enabled classification of patients into favourable, intermediate, and poor risk groups, providing guidance regarding selection and sequencing of therapy (Motzer et al, 2002; Heng et al, 2009; Ljungberg et al, 2010; Patil et al, 2011; Motzer et al, 2011; Heng et al, 2013). However, baseline risk categories are dynamic and can change during treatment (Ko et al, 2015). Therefore, investigation into on-treatment efficacy biomarkers in order to adjust prognosis after starting therapy is warranted.

Several potential serum-, radiological-, and tissue-based biomarkers have been investigated across multiple agents, including circulating soluble proteins associated with angiogenic pathways (e.g., vascular endothelial growth factor (VEGF)), functional imaging, VEGF single-nucleotide polymorphisms, and the tumour marker hypoxia-inducible factor 1-alpha (Schneider et al, 2008; Figlin et al, 2009; Peña et al, 2010; Escudier et al, 2011; GarciaDonas et al, 2011; Xu et al, 2011; Muriel López et al, 2012; Tran et al, 2012; Zurita et al, 2012; Bex et al, 2014; Harmon et al, 2014; Mains et al, 2014). However, none of these biomarkers have been integrated into a prognostic model or validated for use in RCC (Jain et al, 2009). Moreover, given the investment of patient resources, time, cost, and expertise associated with each, none represent an ideal biomarker for clinical use. An alternative to such biomarkers are mechanism-based adverse events (AEs) that reflect 'on-target' effects of a molecularly targeted agent and its inhibition of a given pathway (Dienstmann et al, 2011). Such on-target AEs may be used as surrogates of pharmacokinetic and pharmacodynamic effect, as well as potential predictors of efficacy.

Sunitinib malate (SUTENT; Pfizer Inc., New York, NY, USA) is an oral multitargeted inhibitor of VEGF receptors, platelet-derived growth factor receptors, and other receptor tyrosine kinases that is approved internationally for the treatment of advanced RCC (Sunitinib malate (SUTENT) prescribing information, 2014). Prior retrospective analyses using a pooled database of five prospective sunitinib clinical trials in patients with metastatic RCC (mRCC) identified treatment-associated hypertension as a biomarker of efficacy (Rini et al, 2011). A four-fold improved survival rate was seen in patients who develop hypertension during therapy compared with patients without hypertension.

In the present analyses, we used the same pooled database to separately evaluate hand-foot syndrome, asthenia and/or fatigue, neutropenia, and thrombocytopenia as potential biomarkers of sunitinib efficacy in individual AE models. These AEs were chosen because they are common, manageable, readily, and systematically measurable, and potentially associated with the intended target inhibition of sunitinib. The relative strength and independence of each biomarker, including hypertension, were then assessed in the final combined multivariate analyses. In addition, independent biomarkers were incorporated into our own prognostic model as well as the International Metastatic Renal Cell Carcinoma Database Consortium (IMDC) model (Heng et al, 2013).

\section{MATERIALS AND METHODS}

Patients. Pooled retrospective analyses included patients from five prospective clinical trials (Motzer et al, 2006a, b; Escudier et al, 2009; Motzer et al, 2009; Barrios et al, 2012). Common eligibility criteria included age $\geqslant 18$ years with histologically confirmed mRCC, presence of measurable disease, no known brain metastases, Eastern Cooperative Oncology Group (ECOG) performance status $0 / 1$, and adequate organ function. All patients gave written informed consent.
Study designs and assessments. The analyses included pooled data from 770 mRCC patients who received sunitinib in both the first-line $(n=494 ; 64 \%)$ and cytokine-refractory $(n=276 ; 36 \%)$ treatment settings (Motzer et al, 2006a,b; Escudier et al, 2009; Motzer et al, 2009; Barrios et al, 2012). Sunitinib was administered orally at either a starting dose of $50 \mathrm{mg}$ once daily on a 4 -weekson-2-weeks-off schedule (Schedule 4/2), in repeated 6-week cycles ( $n=544 ; 71 \%)$, or $37.5 \mathrm{mg}$ continuously once daily ( $n=226 ; 29 \%)$. Treatment continued until disease progression, lack of clinical benefit, unacceptable toxicity, or consent withdrawal.

Efficacy end points included objective response (OR) and progression-free survival (PFS), assessed by investigators using Response Evaluation Criteria in Solid Tumours (Therasse et al, 2000) and overall survival (OS). The AEs neutropenia, thrombocytopenia, hand-foot syndrome, and asthenia/fatigue were recorded regularly and graded according to the National Cancer Institute Common Terminology Criteria for Adverse Events (CTCAE), version 3.0, with severity grades for neutropenia and thrombocytopenia based on absolute neutrophil and platelet counts, respectively. The frequency of haematology assessments varied across the studies; however, in general, most patients were assessed at screening within 1-3 weeks prior to study entry, predose on Cycle 1 Day 1, at least every 2 weeks during the first 6-week cycle, and every 4 weeks thereafter until end of treatment or withdrawal. As previously studied (Rini et al, 2011), hypertension was defined by maximum systolic blood pressure (SBP) of $\geqslant 140 \mathrm{~mm} \mathrm{Hg}$, measured in the clinic on Days 1 and 28 of each 6-week treatment cycle. Results of analyses using hypertension defined by diastolic blood pressure $\geqslant 90 \mathrm{~mm} \mathrm{Hg}$ were similar (Rini et al, 2011).

The studies were run in accordance with the International Conference on Harmonization Good Clinical Practice guidelines (or the Declaration of Helsinki) and applicable local regulatory requirements and laws and approved by the institutional review boards or independent ethics committees of each participating centre.

Analytical and statistical methods (individual AE models). In the individual AE models, PFS and OS were estimated by KaplanMeier method, and a log-rank test was used to compare results between groups of patients with $v s$ without the $\mathrm{AE}$ in question: neutropenia (grade $\geqslant 2$ ), thrombocytopenia (grade $\geqslant 2$ ), handfoot syndrome (grade $>0$ ), or asthenia/fatigue (grade $>0$ ). The grade $\geqslant 2$ threshold was chosen for neutropenia and thrombocytopenia based on prior chemotherapy studies in which this severity level for each $\mathrm{AE}$ was associated with improved prognosis and, historically, formed the basis for a dose individualisation approach using 'toxicity-adjusting dosing' (Gurney, 2002). A grade $>0$ threshold was chosen for hand - foot syndrome and asthenia/ fatigue because of the small numbers of patients with higher severity grades for these AEs, limiting the statistical power of using a higher threshold.

The influence on PFS and OS of several prognostic factors, including sunitinib relative dose intensity (the ratio of actually received to intended sunitinib dose) for the overall treatment period and previously identified prognostic factors (including the Memorial Sloan-Kettering Cancer Center (MSKCC) prognostic criteria; Motzer et al, 2002) were analysed using a separate multivariate Cox proportional hazards model for each AE; factors with a $P$-value $<0.2$ in univariate analysis (based on two-sided Wald chi-squared tests) were included in the multivariate model to identify if the $\mathrm{AE}$ in question was a significant independent predictor $(P<0.05)$.

In addition, a Cox proportional hazards model with each $\mathrm{AE}$ as a time-dependent covariate (to address potential bias from longer drug exposure) was used to further estimate hazard ratios for PFS and OS. 
Finally, separate landmark analyses using the Kaplan-Meier method were performed at 6 and 12 weeks for each AE (in which patients were grouped based on the occurrence of the $\mathrm{AE}$ prior to these time points) to assess the correlations between early $\mathrm{AE}$ occurrence and outcome. Patients who died or had disease progression before the landmark time point were excluded from the OS and PFS analyses, respectively.

Analytical and statistical methods (combined AE models). In the final combined $\mathrm{AE}$ analyses, a multivariate Cox proportional hazards regression model was used to simultaneously analyse the independent predictive value of all the preceding $\mathrm{AE}$ biomarkers, including hypertension (Rini et al, 2011) and other prognostic factors, on clinical outcome. Thus the following were used as covariates for association with OR, PFS, and OS: treatment-induced hypertension $(\mathrm{SBP} \geqslant 140 \mathrm{~mm} \mathrm{Hg})$; neutropenia (grade $\geqslant 2$ ); thrombocytopenia (grade $\geqslant 2$ ); hand-foot syndrome (grade $>0$ ); asthenia/fatigue (grade $>0$ ); sunitinib dose reduction; sunitinib relative dose intensity for the overall treatment period; and previously identified prognostic factors, including the MSKCC criteria (Motzer et al, 2002) and prognostic criteria developed for mRCC patients receiving VEGF inhibitors (as integrated into the IMDC model; Heng et al, 2013). (Note: pretreatment hypertension was not included as a covariate, but uncontrolled hypertension was an exclusion criterion in all clinical trials (Pfizer, data on file; Rini et al, 2011). Each factor was investigated in univariate and then multivariate analyses using a Cox proportional hazards model; $P$-values were based on two-sided Wald chi-squared tests.

The multivariate analysis was repeated for PFS and OS using a 12-week landmark (i.e., AEs evaluated up to the first 12 weeks of treatment) to address potential bias from misclassification of patients who may not have remained on study long enough for an AE to be observed. Patients who died or had disease progression before the landmark time point were excluded from the OS and PFS analyses, respectively.

The ability of the AEs hypertension and neutropenia to improve the prognostic accuracy of the IMDC model was evaluated using the concordance index (C-index), which was calculated using individual IMDC scores followed by the addition of hypertension and neutropenia. A C-index of 0.5 represents no predictive discrimination, and a C-index of 1 represents perfect ability to distinguish patients.

To control for the prognostic impact of the baseline status of neutrophil counts, subgroup analyses were performed to evaluate the impact of eight different clinical scenarios ('8-group' analysis) on efficacy outcomes (OR, PFS, and OS). The subgroups were based on combined baseline neutrophil count and nadir neutropenia grade and hypertension status during treatment. PFS and OS were estimated by Kaplan-Meier method, with corresponding 95\% confidence intervals (CIs) calculated. The prognostic impact of adding on-treatment hypertension and neutropenia to baseline IMDC classification was evaluated using OS alone.

All combined AE analyses were performed separately for patients on Schedule 4/2 and on any dose/schedule (Schedule 4/2 and continuous daily dosing combined).

\section{RESULTS}

Patients. The pooled database comprised 770 patients included in five clinical trials. Most patients in these retrospective analyses were male, with median ages ranging from 56 to 62 years in the trials comprising the pooled database (Table 1). More than $98 \%$ had a diagnosis of RCC with clear cell histology, and most had an ECOG performance status of $0 / 1$ and had undergone prior nephrectomy.

Incidences of AEs during treatment. Among the 770 patients included in the analyses, 614 (80\%), 365 (47\%), 172 (22\%), 179 (23\%), and $583(76 \%)$ experienced on-treatment SBP-defined hypertension, neutropenia (grade $\geqslant 2$ ), thrombocytopenia (grade $\geqslant 2$ ), hand-foot syndrome (grade $>0$ ), and asthenia/fatigue (grade $>0$ ), respectively. Hypertension was more frequent than in previous studies because it was defined here by SBP rather than by CTCAE (Sunitinib malate (SUTENT) prescribing information, 2014).

Individual AE models of associations between AEs and efficacy. Hand-foot syndrome, asthenia/fatigue, neutropenia, and thrombocytopenia were all statistically significantly associated with PFS and OS in univariate analyses (Table 2, which includes previously

\begin{tabular}{|c|c|c|c|c|c|}
\hline Characteristic & $\begin{array}{c}\text { Second-line, } \\
\text { Schedule } 4 / 2 \text { phase } \\
\text { II trial (Motzer et al, } \\
\text { 2006a) }(n=63)\end{array}$ & $\begin{array}{l}\text { Second-line, } \\
\text { Schedule } 4 / 2 \text { phase } \\
\text { II trial (Motzer et al, } \\
\text { 2006b) }(n=106)\end{array}$ & $\begin{array}{l}\text { First-line, Schedule } \\
4 / 2 \text { phase III trial } \\
\text { (Motzer et al, 2009) } \\
\quad(n=375)^{\mathrm{a}}\end{array}$ & $\begin{array}{c}\text { First-line, Schedule } \\
\text { CDD phase II trial } \\
\text { (Barrios et al, 2012) } \\
(n=119)\end{array}$ & $\begin{array}{c}\text { Second-line, } \\
\text { Schedule CDD phase } \\
\text { II trial (Escudier et al, } \\
2009)(n=107)\end{array}$ \\
\hline Median (range) age, years & $60(24-87)$ & $56(32-79)$ & $62(27-87)$ & $58^{\mathrm{b}}(24-78)$ & $59(29-80)$ \\
\hline Male/female, n (\%) & $68 / 32$ & $63 / 37$ & $71 / 29$ & $76 / 24$ & $82 / 18$ \\
\hline \multicolumn{6}{|l|}{ ECOG PS, n (\%) } \\
\hline 0 & $34(54)$ & $58(55)$ & $231(62)$ & $63(53)$ & $61(57)$ \\
\hline 1 & $29(46)$ & $48(45)$ & $144(38)$ & $56(47)$ & $45(42)$ \\
\hline$\geqslant 2$ & 0 & 0 & 0 & 0 & $1(1)$ \\
\hline \multicolumn{6}{|l|}{ Histology, n (\%) } \\
\hline Clear cell & $55(87)$ & 105 (99) & $375(100)$ & $119(100)$ & $104(97)$ \\
\hline Other & $8(13)$ & $1(1)$ & 0 & 0 & $3(3)$ \\
\hline Prior nephrectomy, n (\%) & $58(92)$ & $106(100)$ & $340(91)$ & $112(94)$ & $100(93)$ \\
\hline Prior cytokine therapy, n (\%) & $63(100)$ & $106(100)$ & 0 & 0 & $107(100)$ \\
\hline Prior radiation therapy, $n$ (\%) & $25(40)$ & $20(19)$ & $53(14)$ & $15(13)$ & NA \\
\hline \multicolumn{6}{|l|}{ No. of disease sites, n (\%) } \\
\hline 1 & $8(13)$ & $13(12)$ & $55(15)$ & $30(25)$ & $12(11)$ \\
\hline$\geqslant 2$ & $55(87)$ & $93(88)$ & $320(85)$ & $87(73)^{\mathrm{c}}$ & 95 (89) \\
\hline \multicolumn{6}{|c|}{$\begin{array}{l}\text { Abbreviations: } C D D=\text { continuous daily dosing; } E C O G \text { PS }=\text { Eastern Cooperative Oncology Group performance status; } N A=\text { not available. } \\
\text { aThe } 375 \text { patients cited in the table are those who received sunitinib in this trial. } \\
\text { b Mean value presented. }\end{array}$} \\
\hline
\end{tabular}




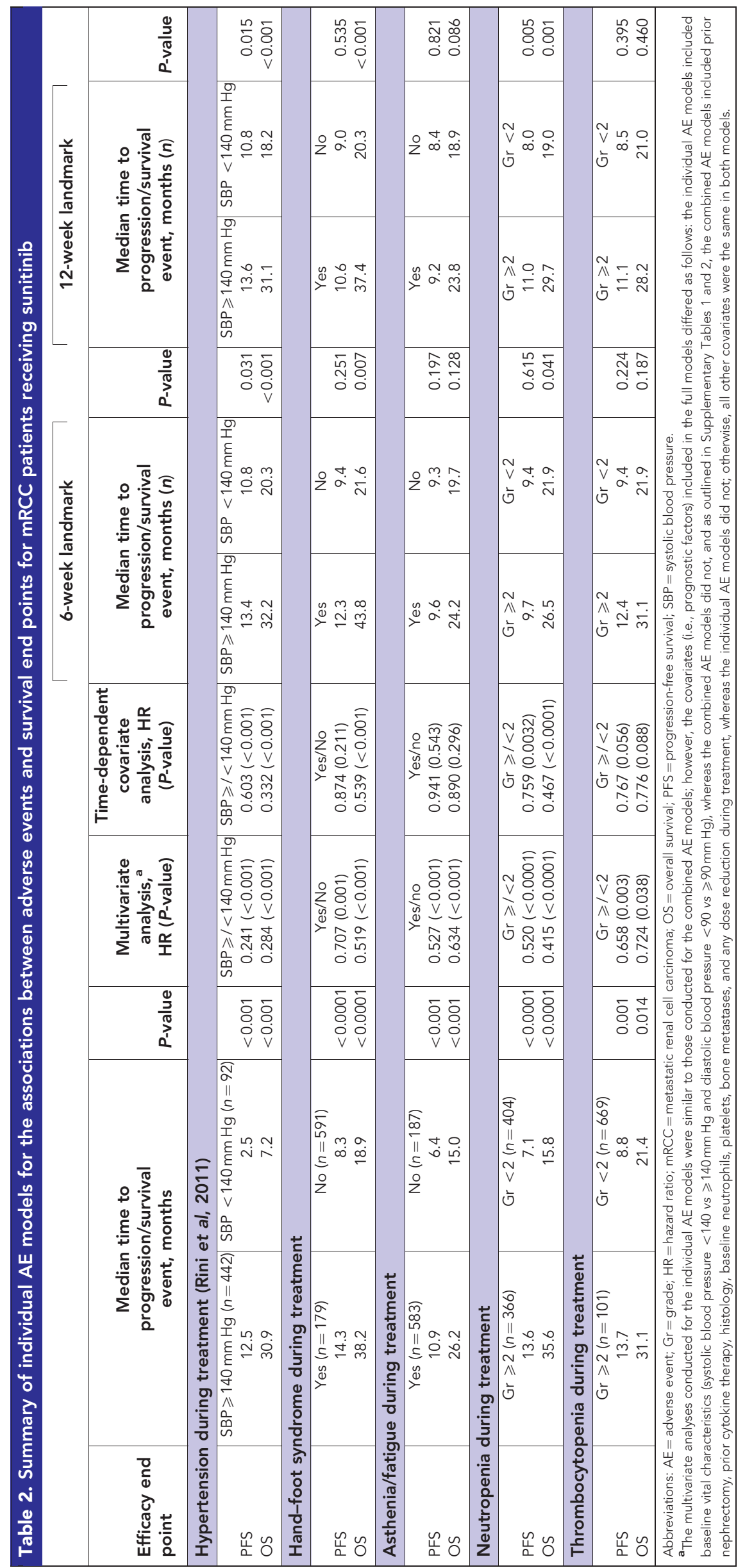


reported data for hypertension). In separate multivariate analyses for each $\mathrm{AE}$, in which established baseline prognostic factors were included and other AEs were omitted, hand-foot syndrome, asthenia/fatigue, neutropenia, and thrombocytopenia were all statistically significantly associated with PFS and OS (Table 2). In addition, both neutropenia and hypertension remained statistically significantly associated with both PFS and OS by time-dependent covariate analysis (Table 2). By separate 12 -week landmark analyses, neutropenia and hypertension were significantly associated with both PFS and OS, and hand-foot syndrome was significantly associated with OS; asthenia/fatigue and thrombocytopenia were not significantly associated with either PFS or OS (Table 2).

Combined AE (final multivariate) models of associations between AEs and efficacy. The final multivariate analyses included hand-foot syndrome, asthenia/fatigue, neutropenia, thrombocytopenia, and hypertension (as previously reported), as well as established baseline prognostic factors, including individual factors integrated in the MSKCC and IMDC prognostic models. Development of any of the five AEs at any time point during sunitinib treatment, regardless of dose/schedule, was statistically significantly associated with greater OR (Table 3, which reports the results for AEs only), independent of baseline prognostic factors (Supplementary Table S1, which includes the full model with results for all covariates). In addition, the occurrence of neutropenia and hypertension during treatment was significantly associated with both longer PFS and OS (Table 4, which reports the results for AEs only), independent of baseline prognostic factors (Supplementary Table S2, which includes the full model with results for all covariates); however, the occurrence of asthenia/ fatigue at any time was significantly associated with longer PFS only, and the occurrence of hand-foot syndrome at any time was significantly associated with longer OS only.

By 12-week landmark analyses (Table 4), neutropenia was significantly associated with both longer PFS and OS, the occurrence of hypertension or hand-foot syndrome was significantly associated with longer OS, and asthenia/fatigue results were not significant in any of the landmark analyses. Results were similar regardless of treatment schedule. In addition, the AEs significantly associated with outcome did so independently of baseline prognostic factors (Supplementary Table S2).

The occurrence of thrombocytopenia was not significantly associated with longer PFS or OS in any of the analyses (at any

Table 3. Final combined AE multivariate models of associations between adverse events and objective response (OR; complete or partial response) for $\mathrm{mRCC}$ patients receiving sunitinib on Schedule $4 / 2$ or any dose/schedule

\begin{tabular}{|c|c|c|c|c|c|c|c|}
\hline \multirow[b]{2}{*}{ Adverse event at any time point } & \multirow[b]{2}{*}{ End point } & \multicolumn{3}{|c|}{ Schedule 4/2 } & \multicolumn{3}{|c|}{ Any dose/schedule } \\
\hline & & Odds ratio & $95 \% \mathrm{Cl}$ & $P$-value ${ }^{a}$ & Odds ratio & $95 \% \mathrm{Cl}$ & $P$-value ${ }^{a}$ \\
\hline Neutropenia & OR & 0.53 & $0.35-0.79$ & 0.0021 & 0.44 & $0.30-0.66$ & $<0.0001$ \\
\hline Hypertension & OR & 0.20 & $0.12-0.34$ & $<0.0001$ & 0.20 & $0.12-0.32$ & $<0.0001$ \\
\hline Hand-foot syndrome & OR & 0.43 & $0.27-0.68$ & 0.0003 & 0.43 & $0.28-0.66$ & 0.0001 \\
\hline Asthenia/fatigue & OR & 0.44 & $0.28-0.70$ & 0.0005 & 0.48 & $0.32-0.73$ & 0.0007 \\
\hline Thrombocytopenia & OR & 0.54 & $0.33-0.87$ & 0.0118 & 0.55 & $0.35-0.86$ & 0.0098 \\
\hline
\end{tabular}

Table 4. Final combined AE multivariate models of associations between adverse events and survival end points for mRCC patients receiving sunitinib on (A) Schedule $4 / 2$ or (B) any dose/schedule

\begin{tabular}{|c|c|c|c|c|c|c|c|}
\hline \multirow[b]{2}{*}{ Adverse event } & \multirow[b]{2}{*}{ End point } & \multicolumn{3}{|c|}{ Adverse event at any time point } & \multicolumn{3}{|c|}{ Adverse event by the 12-week landmark } \\
\hline & & HR & $95 \% \mathrm{Cl}$ & $P$-value ${ }^{a}$ & HR & $95 \% \mathrm{Cl}$ & $P$-value ${ }^{a}$ \\
\hline \multicolumn{8}{|l|}{ (A) Schedule 4/2 } \\
\hline \multirow[t]{2}{*}{ Neutropenia } & PFS & 0.77 & $0.61-0.97$ & 0.0276 & 0.72 & $0.56-0.93$ & 0.0130 \\
\hline & OS & 0.65 & $0.50-0.85$ & 0.0014 & 0.71 & $0.55-0.93$ & 0.0122 \\
\hline \multirow[t]{2}{*}{ Hypertension } & PFS & 0.37 & $0.27-0.52$ & $<0.0001$ & 0.81 & $0.61-1.07$ & 0.1305 \\
\hline & OS & 0.36 & $0.27-0.50$ & $<0.0001$ & 0.68 & $0.53-0.88$ & 0.0036 \\
\hline \multirow[t]{2}{*}{ Hand-foot syndrome } & PFS & 0.90 & $0.70-1.15$ & 0.3986 & 0.83 & $0.59-1.16$ & 0.2651 \\
\hline & OS & 0.70 & $0.52-0.93$ & 0.0152 & 0.64 & $0.44-0.94$ & 0.0218 \\
\hline \multirow[t]{2}{*}{ Asthenia/fatigue } & PFS & 0.56 & $0.42-0.74$ & $<0.0001$ & 1.01 & $0.78-1.30$ & 0.9555 \\
\hline & OS & 0.82 & $0.61-1.10$ & 0.1882 & 0.99 & $0.78-1.27$ & 0.9586 \\
\hline \multirow[t]{2}{*}{ Thrombocytopenia } & PFS & 0.83 & $0.63-1.10$ & 0.1971 & 1.05 & $0.73-1.51$ & 0.7905 \\
\hline & OS & 0.96 & $0.70-1.33$ & 0.8271 & 1.07 & $0.74-1.53$ & 0.7233 \\
\hline \multicolumn{8}{|c|}{ (B) Any dose/schedule } \\
\hline \multirow[t]{2}{*}{ Neutropenia } & PFS & 0.69 & $0.56-0.85$ & 0.0004 & 0.72 & $0.57-0.91$ & 0.0062 \\
\hline & OS & 0.58 & $0.45-0.73$ & $<0.0001$ & 0.68 & $0.53-0.87$ & 0.0019 \\
\hline \multirow[t]{2}{*}{ Hypertension } & PFS & 0.44 & $0.33-0.58$ & $<0.0001$ & 0.98 & $0.76-1.26$ & 0.8730 \\
\hline & OS & 0.48 & $0.37-0.63$ & $<0.0001$ & 0.73 & $0.58-0.91$ & 0.0063 \\
\hline \multirow[t]{2}{*}{ Hand-foot syndrome } & PFS & 0.88 & $0.70-1.10$ & 0.2495 & 0.88 & $0.64-1.19$ & 0.3963 \\
\hline & OS & 0.69 & $0.52-0.90$ & 0.0062 & 0.60 & $0.42-0.86$ & 0.0049 \\
\hline \multirow[t]{2}{*}{ Asthenia/fatigue } & PFS & 0.69 & $0.54-0.88$ & 0.0026 & 0.98 & $0.79-1.23$ & 0.8786 \\
\hline & OS & 0.94 & $0.73-1.22$ & 0.6576 & 0.96 & $0.77-1.19$ & 0.7056 \\
\hline \multirow[t]{2}{*}{ Thrombocytopenia } & PFS & 0.96 & $0.75-1.24$ & 0.7557 & 1.09 & $0.79-1.51$ & 0.5920 \\
\hline & OS & 1.00 & $0.76-1.32$ & 0.9863 & 1.11 & $0.81-1.52$ & 0.5096 \\
\hline $\begin{array}{l}\text { Abbreviations: } A E=\text { adve } \\
\text { significant results are in b } \\
\text { a }{ }^{\text {Two-sided Wald chi-squ }}\end{array}$ & & & & & & $=$ progressior & rvival. Statis \\
\hline
\end{tabular}



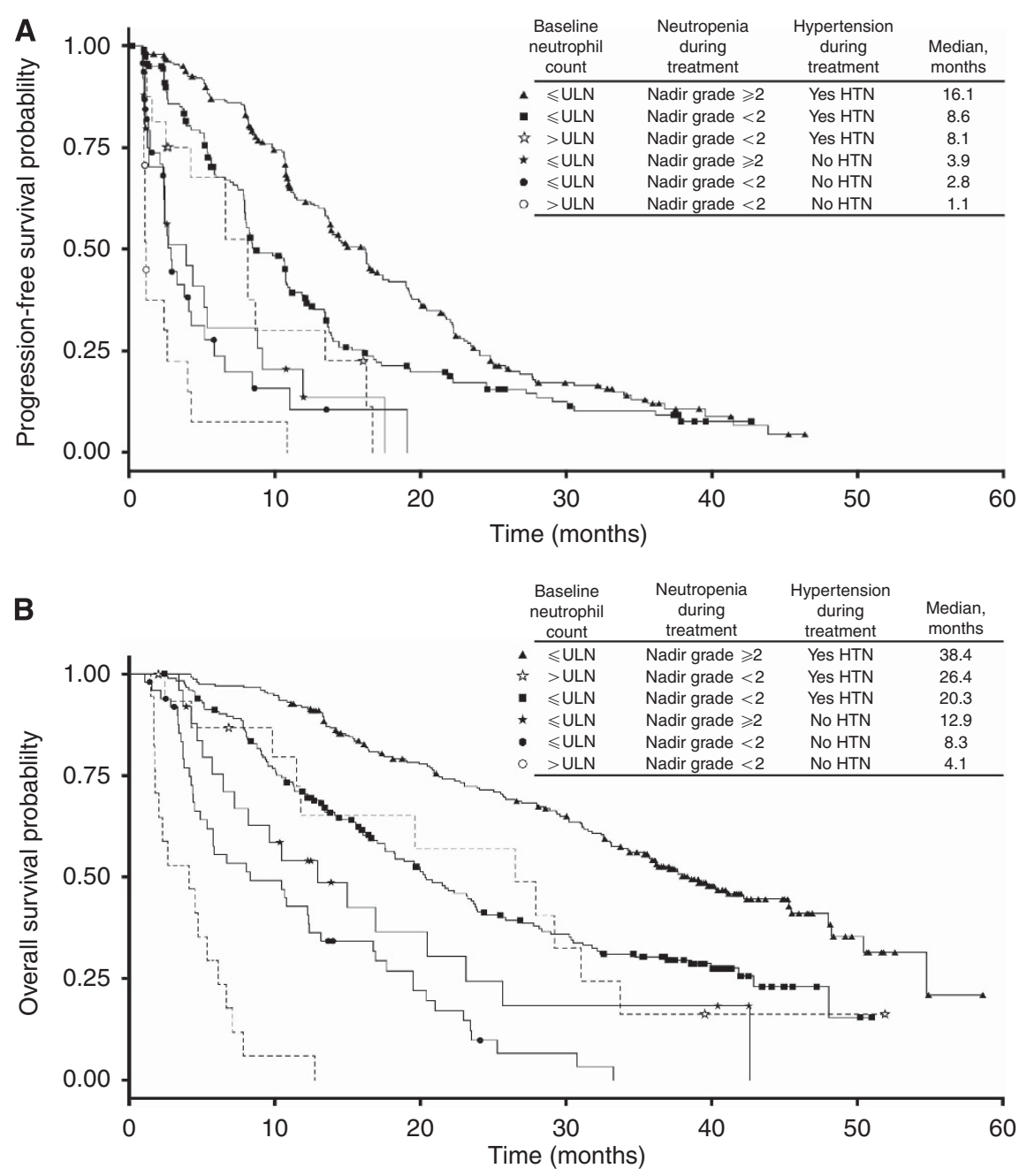

Figure 1. Prognostic model based on baseline neutrophil status (normal vs elevated) with the addition of on-treatment status of hypertension (HTN; yes vs no) and neutropenia (yes vs no) ('8-group' analysis). All patients were treated with sunitinib on Schedule 4/2. (A) PFS; (B) OS.

$\mathrm{ULN}=$ upper limit of normal.

time point or in the 12-week landmark analyses), regardless of treatment schedule (Table 4).

The C-index for IMDC classification alone was 0.65 (95\%: CI $0.63-0.67)$, increasing to 0.72 (95\% CI: $0.70-0.74)$ for IMDC combined with hypertension and neutropenia.

Dose reduction for any reason, which was also included as a covariate in the multivariate analysis models, was significantly associated with improved efficacy outcomes (OR, PFS, and OS) in the analyses of AEs occurring at any time point and regardless of treatment schedule (Supplementary Tables S1 and S2); however, it was not significantly associated with survival outcomes (PFS and OS) in the 12-week landmark analyses (Supplementary Table S2).

According to change-from-baseline (Cox proportional hazards) analyses in which asthenia/fatigue and hand-foot syndrome were excluded (data not shown), the following factors were significantly associated with PFS: $(1) \geqslant 10$ (or $\geqslant 15$ ) $\mathrm{mm} \mathrm{Hg}$ change in SBP or a change in SBP $\geqslant$ median (of the maximum change from baseline) and (2) a change in neutrophil counts $\geqslant$ median (of the worst change from baseline). The change-from-baseline analyses found that the same changes in SBP were also significantly associated with OS and that a change in platelet counts $\geqslant$ median (of the worst change from baseline) was significantly associated with OS as well. Although these analyses did not duplicate the findings of the combined multivariate analyses (owing to the lack of association between changes in neutrophil counts and OS), they were generally supportive.
Incorporating biomarkers into a prognostic model. We examined the impact of on-treatment hypertension and neutropenia in combination with established baseline risk factors. First, we used a simple model based on baseline neutrophil status, that is, elevated $v s$ normal ( $\leqslant$ upper limit of normal; Figure 1 and Supplementary Table S3). Patients on Schedule $4 / 2$ with elevated baseline neutrophil counts who did not subsequently experience neutropenia or hypertension during therapy had an OR rate (ORR) of $0 \%$, median PFS of 1.1 months, and median OS of 4.1 months. Almost no patients with elevated baseline neutrophils, regardless of dose/ schedule, experienced neutropenia. However, if patients on Schedule $4 / 2$ with elevated baseline neutrophils subsequently experienced hypertension during therapy, they had an ORR of $44 \%$, median PFS of 8.1 months, and median OS of 26.4 months. Patients with normal neutrophil counts at baseline who subsequently experienced both on-treatment neutropenia and hypertension had an ORR of 65\%, median PFS of 16.1 months, and median OS of 38.4 months.

We next used the IMDC prognostic model. For patients categorised in the IMDC favourable-, intermediate-, and poor-risk groups, the median OS was $37.9,19.9$, and 8.0 months, respectively (Figure 2A). Patients in the favourable-risk group were then analysed by adding on-treatment hypertension and neutropenia. For patients in the favourable-risk group with both hypertension and neutropenia compared with no hypertension and neutropenia, median OS more than doubled (45.3 vs 19.5 months) (Figure 2B). 

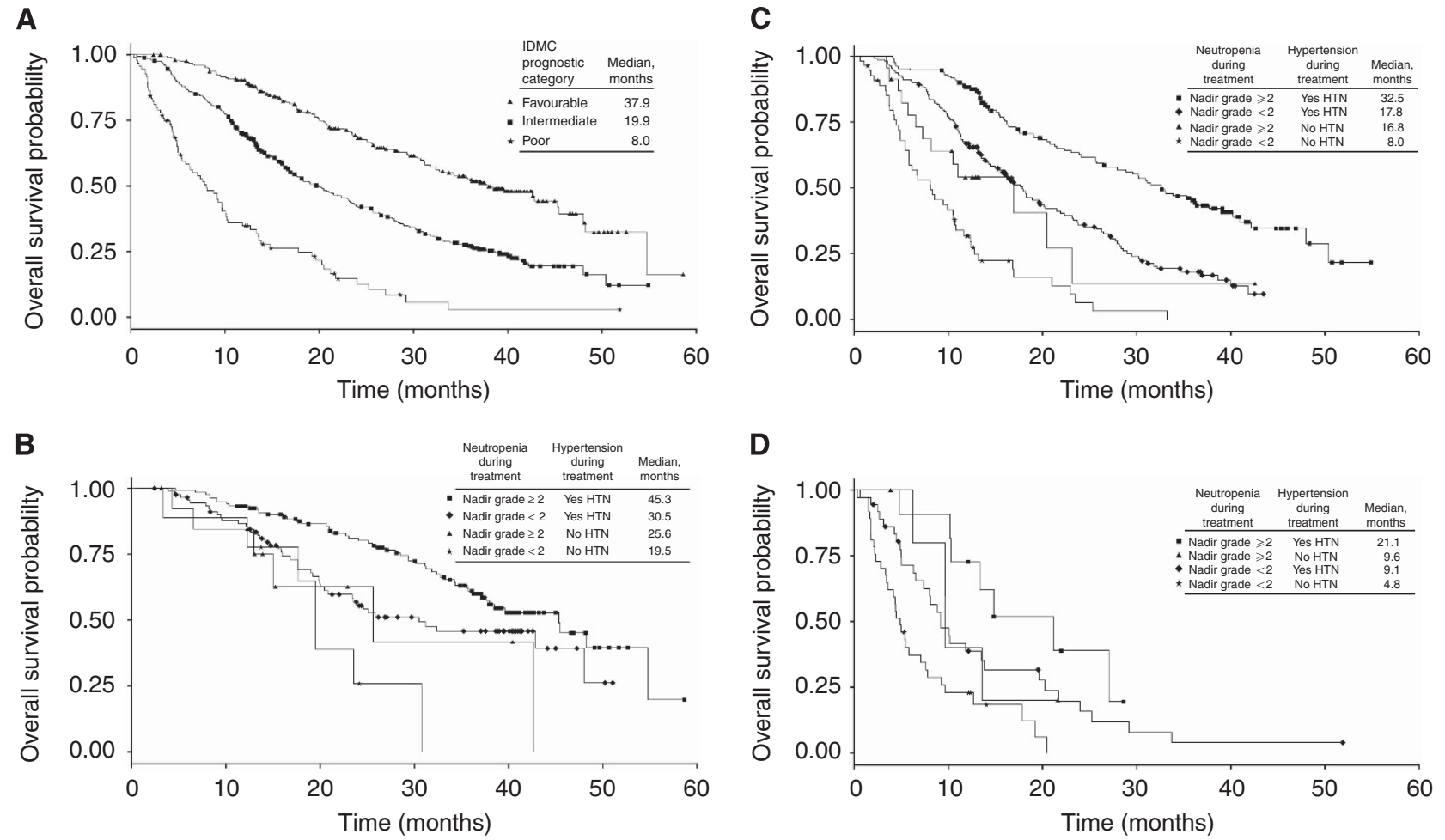

Figure 2. Incorporating on-treatment neutropenia and hypertension into the IMDC model leads to improved prognostic accuracy. Prognostic model based on (A) baseline IMDC status, with the addition of on-treatment status of neutropenia and hypertension in patients with (B) IMDC favourable prognosis, (C) IMDC intermediate prognosis and (D) IMDC poor prognosis.

For patients in the intermediate-risk group with both hypertension and neutropenia compared with no hypertension and no neutropenia, median OS was four-fold longer (32.5 vs 8.0 months) (Figure 2C). For patients in the poor-risk group who developed both hypertension and neutropenia compared with no hypertension and neutropenia, median OS was also four-fold longer (21.1 vs 4.8 months) (Figure 2D).

\section{DISCUSSION}

The present study is the largest and the most comprehensive assessment of known prognostic factors and multiple on-treatment toxicities in patients with mRCC. We demonstrated that ontreatment development of neutropenia and hypertension and, to a lesser degree, hand-foot syndrome, are independent biomarkers of sunitinib efficacy. Development of neutropenia or hypertension or, to a lesser degree, hand-foot syndrome, on treatment predicted improved outcomes, and development of both neutropenia and hypertension predicted even better outcomes. Moreover, incorporating on-treatment neutropenia and hypertension into the IMDC model appeared to add prognostic accuracy.

Recently, Ko et al (2015) demonstrated that baseline-risk categories are dynamic and change during treatment. In patients whose prognosis was evaluated using IMDC criteria prior to both first- and second-line therapy, approximately $40 \%$ had changes in their initial prognostic assessment: from poor to intermediate, favourable to intermediate, or intermediate to poor prognosis. Thus baseline-risk allocations into prognostic categories are not static but are dynamic variables that need readjustment during therapy. Our finding that addition of on-treatment hypertension and neutropenia to baseline IMDC prognostic information predicted a four-fold survival difference within both the IMDC intermediate- and poor-risk groups, and a two-fold survival difference in the favourable-risk group points to hypertension and neutropenia as simple means of adjusting prognosis during first-line therapy. Accurate reassessment of prognosis during therapy may translate group-level prognostic information into individual patient-level information, thereby improving prognostication during treatment. Moreover, failure to develop neutropenia and/or hypertension on treatment could be included as a stratification factor in prospective studies assessing whether dose adjustment or switching to an alternative treatment strategy may change clinical outcome.

The results of these analyses are consistent with the known mechanisms by which sunitinib induces these AEs and how these mechanisms relate to disease progression. With regard to myelosuppression, because stem cell factor receptor and FMS-like tyrosine kinase 3 , as well as VEGF receptors, are involved in hematopoietic cell proliferation and differentiation, their inhibition by sunitinib may cause myelosuppression through on-target mechanisms (Kumar et al, 2009). This explains why neutropenia, albeit mostly grade $1 / 2$ in severity, is frequently associated with sunitinib treatment (Sunitinib malate (SUTENT) prescribing information, 2014). In addition, several studies have demonstrated that tumours stimulate neutrophils to promote angiogenesis (e.g., via release of neutrophil-derived VEGF) and immunosuppression, as well as migration, invasion, and metastasis; that may explain the poor prognosis of patients with pretreatment neutrophilia (Donskov, 2013), which may or may not be overcome by therapy (Taichman et al, 1997; Jensen et al, 2009; Carus et al, 2013; Dumitru et al, 2013). However, this may also explain why sunitinib-induced neutropenia is associated with clinical benefit. With regard to hypertension, VEGF inhibition has been shown to decrease nitric oxide production, leading to vasculature constriction and a reduction in sodium ion renal excretion, resulting in hypertension (Hood et al, 1998; Van Heeckeren et al, 2007), with 
evidence of the involvement of other renovascular mechanisms as well (Dechend and Luft, 2008). As previously hypothesised (Rini et al, 2011), the susceptibility of blood vessels to VEGF blockade, resulting in hypertension, may also be linked to the susceptibility of tumour vessels to VEGF blockade, providing a biological underpinning for the biomarker results. Of note, however, the prior hypertension analyses also found that baseline antihypertensive medication use was significantly associated with longer OS and that the addition of antihypertensive medication during sunitinib treatment did not negatively impact improved survival for hypertensive patients (Rini et al, 2011). These findings suggested the possibility of inherent host biology independent of VEGF inhibition that predisposes patients to a favourable outcome. Such a hypothesis would be compatible with our findings, in which hypertension was significantly associated with OS, but not PFS, in the 12-week landmark analyses and also explain the apparent additive interaction between on-treatment hypertension and neutropenia associated with prolonged survival in the prognostic model analysis. Dose reduction was also not significantly associated with survival outcomes in the 12-week landmark analyses, supporting the hypothesis that hypertension, neutropenia, and hand-foot syndrome are a reflection of underlying tumour biology rather than simply a reflection of higher sunitinib exposure. Further research into underlying biological mechanisms and methods for using these biomarkers to optimise therapy for individual patients is warranted.

Our results obtained in patients participating in clinical trials are consistent with recent data from non-trial patients with mRCC treated with sunitinib at a single institution (Rautiola et al, 2014) and with recent data from a complete national cohort of patients with mRCC treated with first-line tyrosine kinase inhibitors or interleukin-2-based immunotherapy, assessed within the first 12 weeks of treatment (Soerensen et al, in press). Taken together, ontreatment hypertension and neutropenia may therefore be considered to be new, independent, validated prognostic factors. Our study is the first to demonstrate a clear adjustment in the prognosis of all IMDC risk subgroups by adding on-treatment hypertension and neutropenia to baseline IMDC risk classification.

These analyses employed a large database, providing a robust data set. However, in addition to the usual issues associated with retrospective analyses (e.g., lack of internal validation), the following limitations may have confounded results: variability in $\mathrm{AE}$ assessment among the studies (e.g., particularly for subjective AEs such as asthenia/fatigue), including lack of central laboratory assessment of neutrophil and platelet counts and variation in their assessment frequency across studies; and lack of pharmacokinetic data coinciding with the occurrence of each $\mathrm{AE}$ biomarker, precluding investigation of the potential impact of drug exposure (although the fact that not all AEs evaluated were identified as independent biomarkers decreases the likelihood of such an epiphenomenon). Also, there may be other potential AEs that should have been included in this analysis, such as sunitinibinduced hypothyroidism, which has been reported as a potential biomarker (Schmidinger et al, 2011) (routine monitoring of thyroid function tests was not standard within the early clinical studies of sunitinib used in our analyses, and therefore these data are incomplete, precluding their inclusion). In addition, the clinical utility of a 12-week landmark for biomarker analysis rather than an earlier time point may be limited.

In conclusion, the analyses reported herein identify ontreatment neutropenia and hypertension as prognostic factors. Moreover, incorporating hypertension and neutropenia into the IMDC model leads to improved prognostic accuracy. Thus identification of neutropenia and hypertension and, to a lesser degree, hand-foot syndrome, during sunitinib therapy may enable physicians to predict which patients are mostly likely to benefit from therapy. Moreover, lack of neutropenia and/or hypertension within 12 weeks could be incorporated as a stratification factor in prospective studies assessing whether dose adjustment or switching to an alternative treatment strategy may change clinical outcome. In the meantime, providers who observe these AEs in their patients should be encouraged to continue sunitinib therapy, while managing AEs with standard medical treatment, with or without dosing interruption and/or dose reduction, as clinically indicated.

\section{ACKNOWLEDGEMENTS}

We thank all the participating patients and their families, as well as the investigators, research nurses, study coordinators, and operation staff. This study was sponsored by Pfizer Inc., New York, NY, USA. Medical writing support was provided by Andy Gannon at ACUMED, part of the KnowledgePoint360 Group, an Ashfield company (New York, NY, USA) with funding from Pfizer Inc.

\section{CONFLICT OF INTEREST}

F Donskov has received research funding from Pfizer, Novartis, and GlaxoSmithKline. GA Bjarnason has received research funding and consulting fees from Pfizer. RJ Motzer has received research funding and consultant fees from Pfizer and has been compensated for expert testimony by Pfizer. D Goldstein has received research funding from Pfizer and GlaxoSmithKline. X Lin, DP Cohen, and R Wiltshire are full-time employees of Pfizer with Pfizer stock. BI Rini has received research funding and consulting fees from Pfizer. The other authors declare no conflict of interest.

\section{AUTHOR CONTRIBUTIONS}

Conception and design: F Donskov, BI Rini; development of methodology: F Donskov, X Lin, BI Rini; acquisition of data: MD Michaelson, I Puzanov, MP Davis, GA Bjarnason, RJ Motzer, D Goldstein; analysis and interpretation of data: F Donskov, X Lin, DP Cohen, BI Rini; writing, review, and/or revision of the manuscript: all authors; administrative, technical, or material support (i.e., reporting or organising data, constructing databases): X Lin; Study supervision: BI Rini.

\section{REFERENCES}

Barrios CH, Hernandez-Barajas D, Brown MP, Lee SH, Fein L, Liu JH, Hariharan S, Martell BA, Yuan J, Bello A, Wang Z, Mundayat R, Rha SY (2012) Phase II trial of continuous once-daily dosing of sunitinib as firstline treatment in patients with metastatic renal cell carcinoma. Cancer 118: $1252-1259$

Bex A, Fournier L, Lassau N, Mulders P, Nathan P, Oyen WJ, Powles T (2014) Assessing the response to targeted therapies in renal cell carcinoma: technical insights and practical considerations. Eur Urol 65: 766-777.

Carus A, Gurney H, Gebski V, Harnett P, Hui R, Kefford R, Wilcken N, Ladekarl M, von der Maase H, Donskov F (2013) Impact of baseline and nadir neutrophil index in non-small cell lung cancer and ovarian cancer patients: assessment of chemotherapy for resolution of unfavourable neutrophilia. J Transl Med 11: 189.

Dechend R, Luft FC (2008) Angiogenesis factors and preeclampsia. Nature Med 14: 1187-1188.

Dienstmann R, Braña I, Rodon J, Tabernero J (2011) Toxicity as a biomarker of efficacy of molecular targeted therapies: focus on EGFR and VEGF inhibiting anticancer drugs. Oncologist 16: 1729-1740.

Donskov F (2013) Immunomonitoring and prognostic relevance of neutrophils in clinical trials. Semin Cancer Biol 23: 200-207. 
Dumitru CA, Lang S, Brandau S (2013) Modulation of neutrophil granulocytes in the tumor microenvironment: mechanisms and consequences for tumor progression. Semin Cancer Biol 23: 141-148.

Escudier B, Loomis AK, Kaprin A, Motzer R, Tomczak P, Tarazi J, Kim S, Gao F, Williams JA, Rini B (2011) Association of single nucleotide polymorphisms (SNPs) in VEGF pathway genes with progression-free survival (PFS) and blood pressure in metastatic renal cell carcinoma (mRCC) in the phase 3 trial of axitinib vs sorafenib (AXIS trial). In: European Multidisciplinary Cancer Congress on Integrating Basic and Translational Science, Surgery, Radiotherapy, Medical Oncology, Advocacy and Care. Eur J Cancer 47: S505 (abstract 7103).

Escudier B, Roigas J, Gillessen S, Harmenberg U, Srinivas S, Mulder SF, Fountzilas G, Peschel C, Flodgren P, Maneval EC, Chen I, Vogelzang NJ (2009) Phase II study of sunitinib administered in a continuous once-daily dosing regimen in patients with cytokine-refractory metastatic renal cell carcinoma. J Clin Oncol 27: 4068-4075.

Figlin RA, de Souza P, McDermott D, Dutcher JP, Berkenblit A, Thiel A, Krygowski M, Strahs A, Feingold J, Boni J, Hudes G (2009) Analysis of PTEN and HIFlalpha and correlation with efficacy in patients with advanced renal cell carcinoma treated with temsirolimus versus interferon-alpha. Cancer 115: 3651-3660.

Garcia-Donas J, Esteban E, Leandro-García LJ, Castellano DE, del Alba AG, Climent MA, Arranz JA, Gallardo E, Puente J, Bellmunt J, Mellado B, Martínez E, Moreno F, Font A, Robledo M, Rodríguez-Antona C (2011) Single nucleotide polymorphism associations with response and toxic effects in patients with advanced renal cell carcinoma treated with firstline sunitinib: a multicentre, observational, prospective study. Lancet Oncol 12: 1143-1150.

Gurney H (2002) How to calculate the dose of chemotherapy. Br J Cancer 86: 1297-1302.

Harmon CS, Deprimo SE, Figlin RA, Hudes GR, Hutson TE, Michaelson MD, Négrier S, Kim ST, Huang X, Williams JA, Eisen T, Motzer RJ (2014) Circulating proteins as potential biomarkers of sunitinib and interferon- $\alpha$ efficacy in treatment-naïve patients with metastatic renal cell carcinoma. Cancer Chemother Pharmacol 73: 151-161.

Heng DY, Xie W, Regan MM, Warren MA, Golshayan AR, Sahi C, Eigl BJ, Ruether JD, Cheng T, North S, Venner P, Knox JJ, Chi KN,

Kollmannsberger C, McDermott DF, Oh WK, Atkins MB, Bukowski RM, Rini BI, Choueiri TK (2009) Prognostic factors for overall survival in patients with metastatic renal cell carcinoma treated with vascular endothelial growth factor-targeted agents: results from a large, multicenter study. J Clin Oncol 27: 5794-5799.

Heng DY, Xie W, Regan MM, Harshman LC, Bjarnason GA, Vaishampayan UN, Mackenzie M, Wood L, Donskov F, Tan MH, Rha SY, Agarwal N,

Kollmannsberger C, Rini BI, Choueiri TK (2013) External validation and comparison with other models of the International Metastatic Renal-Cell Carcinoma Database Consortium prognostic model: a population-based study. Lancet Oncol 14: 141-148.

Hood JD, Meininger CJ, Ziche M, Granger HJ (1998) VEGF upregulates ecNOS message, protein, and NO production in human endothelial cells. Am J Physiol 274: H1054-H1058.

Jain RK, Duda DG, Willett CG, Sahani DV, Zhu AX, Loeffler JS, Batchelor TT, Sorensen AG (2009) Biomarkers of response and resistance to antiangiogenic therapy. Nat Rev Clin Oncol 6: 327-338.

Jensen HK, Donskov F, Marcussen N, Nordsmark M, Lundbeck F, von der Maase H (2009) Presence of intratumoral neutrophils is an independent prognostic factor in localized renal cell carcinoma. J Clin Oncol 27: 4709-4717.

Ko JJ, Xie W, Kroeger N, Lee JL, Rini BI, Knox JJ, Bjarnason GA, Srinivas S, Pal SK, Yuasa T, Smoragiewicz M, Donskov F, Kanesvaran R, Wood L, Ernst DS, Agarwal N, Vaishampayan UN, Rha SY, Choueiri TK, Heng DY (2015) The International Metastatic Renal Cell Carcinoma Database Consortium model as a prognostic tool in patients with metastatic renal cell carcinoma previously treated with first-line targeted therapy: a population-based study. Lancet Oncol 16: 293-300.

Kumar R, Crouthamel M-C, Rominger DH, Gontarek RR, Tummino PJ, Levin RA, King AG (2009) Myelosuppression and kinase selectivity of multikinase angiogenesis inhibitors. Br J Cancer 101: 1717-1723.

Ljungberg B, Cowan NC, Hanbury DC, Hora M, Kuczyk MA, Merseburger AS, Patard JJ, Mulders PF, Sinescu IC. on behalf of the European Association of Urology Guideline Group (2010) European Association of Urology (EAU) Guideline Group. EAU guidelines on renal cell carcinoma: the 2010 update. Eur Urol 58: 398-406.
Mains JR, Donskov F, Pedersen EM, Madsen HH, Rasmussen F (2014) Dynamic contrast-enhanced computed tomography as a potential biomarker in patients with metastatic renal cell carcinoma: preliminary results from the Danish Renal Cancer Group Study-1. Invest Radiol 49: 601-607.

Motzer RJ, Agarwal N, Beard C (2011) National Comprehensive Cancer Network (NCCN) Clinical Practice Guidelines in Oncology for Kidney Cancer, version 1.2011. Available at www.NCCN.org/professionals/ physician_gls/PDF/kidney.pdf (accessed 5 January 2011).

Motzer RJ, Bacik J, Murphy BA, Russo P, Mazumdar M (2002) Interferon-alfa as a comparative treatment for clinical trials of new therapies against advanced renal cell carcinoma. J Clin Oncol 20: 289-296.

Motzer RJ, Hutson TE, Tomczak P, Michaelson MD, Bukowski RM, Oudard S, Negrier S, Szczylik C, Pili R, Bjarnason GA, Garcia-del-Muro X, Sosman JA, Solska E, Wilding G, Thompson JA, Kim ST, Chen I, Huang X, Figlin RA (2009) Overall survival and updated results for sunitinib compared with interferon alfa in patients with metastatic renal cell carcinoma. J Clin Oncol 27: $3584-3590$.

Motzer RJ, Michaelson MD, Redman BG, Hudes GR, Wilding G, Figlin RA, Ginsberg MS, Kim ST, Baum CM, DePrimo SE, Li JZ, Bello CL, Theuer CP, George DJ, Rini BI (2006a) Activity of SU11248, a multitargeted inhibitor of vascular endothelial growth factor receptor and plateletderived growth factor receptor, in patients with metastatic renal cell carcinoma. J Clin Oncol 24: 16-24.

Motzer RJ, Rini BI, Bukowski RM, Curti BD, George DJ, Hudes GR, Redman BG, Margolin KA, Merchan JR, Wilding G, Ginsberg MS, Bacik J, Kim ST, Baum CM, Michaelson MD (2006b) Sunitinib in patients with metastatic renal cell carcinoma. JAMA 295: 2516-2524.

Muriel López C, Esteban E, Astudillo A, Pardo P, Berros JP, Izquierdo M, Crespo G, Fonseca PJ, Sanmamed M, Martínez-Camblor P (2012) Predictive factors for response to treatment in patients with advanced renal cell carcinoma. Invest New Drugs 30: 2443-2449.

Patil S, Figlin RA, Hutson TE, Michaelson MD, Négrier S, Kim ST, Huang X, Motzer RJ (2011) Prognostic factors for progression-free and overall survival with sunitinib targeted therapy and with cytokine as first-line therapy in patients with metastatic renal cell carcinoma. Ann Oncol 22: 295-300.

Peña C, Lathia C, Shan M, Escudier B, Bukowski RM (2010) Biomarkers predicting outcome in patients with advanced renal cell carcinoma: results from sorafenib phase III treatment approaches in Renal Cancer Global Evaluation Trial. Clin Cancer Res 16: 4853-4863.

Rautiola J, Donskov F, Peltola K, Joensuu H, Bono P (2014) Sunitinib-induced hypertension, neutropenia and thrombocytopenia as predictors of good prognosis in metastatic renal cell carcinoma patients. BJU Int; e-pub ahead of print 23 September 2014; doi:10.1111/bju.12940.

Rini BI, Cohen DP, Lu DR, Chen I, Hariharan S, Gore ME, Figlin RA, Baum MS, Motzer RJ (2011) Hypertension as a biomarker of efficacy in patients with metastatic renal cell carcinoma treated with sunitinib. J Natl Cancer Inst 103: 763-773.

Schmidinger M, Vogl UM, Bojic M, Lamm W, Heinzl H, Haitel A, Clodi M, Kramer G, Zielinski CC (2011) Hypothyroidism in patients with renal cell carcinoma: blessing or curse? Cancer 117: 534-544.

Schneider BP, Wang M, Radovich M, Sledge GW, Badve S, Thor A, Flockhart DA, Hancock B, Davidson N, Gralow J, Dickler M, Perez EA, Cobleigh M, Shenkier T, Edgerton S, Miller KD. on behalf of ECOG 2100 (2008) Association of vascular endothelial growth factor and vascular endothelial growth factor receptor-2 genetic polymorphisms with outcome in a trial of paclitaxel compared with paclitaxel plus bevacizumab in advanced breast cancer: ECOG 2100. J Clin Oncol 26: 4672-4678Erratum in: J Clin Oncol (2009) 27: 3070.

Soerensen AV, Geertsen PF, Christensen IJ, Hermann GG, Jensen NV, Fode K, Petersen A, Sandin R, Donskov F (2015) A 5-factor biomarker profile obtained week 4 to 12 of treatment for improved prognostication in metastatic renal cell carcinoma: results from DARENCA study 2. Acta Oncol; e-pub ahead of print 8 October 2015.

Sunitinib malate (SUTENT) prescribing information (2014) Revised 08/13. Available at http://www.sutent.com (accessed 30 January 2014).

Taichman NS, Young S, Cruchley AT, Taylor P, Paleolog E (1997) Human neutrophils secrete vascular endothelial growth factor. J Leukoc Biol 62 : 397-400.

Therasse P, Arbuck SG, Eisenhauer EA, Wanders J, Kaplan RS, Rubinstein L, Verweij J, Van Glabbeke M, van Oosterom AT, Christian MC, Gwyther SG (2000) New guidelines to evaluate the response to treatment in solid tumors. European Organization for Research and Treatment of Cancer, National 
Cancer Institute of the United States, National Cancer Institute of Canada. J Natl Cancer Inst 92: 205-216.

Tran HT, Liu Y, Zurita AJ, Lin Y, Baker-Neblett KL, Martin AM, Figlin RA, Hutson TE, Sternberg CN, Amado RG, Pandite LN, Heymach JV (2012) Prognostic or predictive plasma cytokines and angiogenic factors for patients treated with pazopanib for metastatic renal-cell cancer: a retrospective analysis of phase 2 and phase 3 trials. Lancet Oncol 13: $827-837$.

Van Heeckeren WJ, Ortiz J, Cooney MM, Remick SC (2007) Hypertension, proteinuria, and antagonism of vascular endothelial growth factor signaling: clinical toxicity, therapeutic target, or novel biomarker? J Clin Oncol 25: 2993-2995.

Xu CF, Bing NX, Ball HA, Rajagopalan D, Sternberg CN, Hutson TE, de Souza P, Xue ZG, McCann L, King KS, Ragone LJ, Whittaker JC, Spraggs CF,
Cardon LR, Mooser VE, Pandite LN (2011) Pazopanib efficacy in renal cell carcinoma: evidence for predictive genetic markers in angiogenesis-related and exposure-related genes. J Clin Oncol 29: 2557-2564.

Zurita AJ, Jonasch E, Wang X, Khajavi M, Yan S, Du DZ, Xu L, Herynk MH, McKee KS, Tran HT, Logothetis CJ, Tannir NM, Heymach JV (2012) A cytokine and angiogenic factor (CAF) analysis in plasma for selection of sorafenib therapy in patients with metastatic renal cell carcinoma. Ann Oncol 23: 46-52.

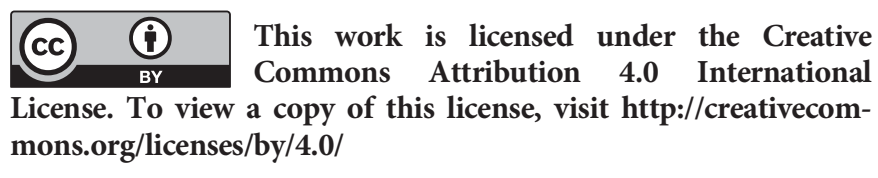

Supplementary Information accompanies this paper on British Journal of Cancer website (http://www.nature.com/bjc) 